\title{
Effect of Cationic and Anionic Porphyrins on the Structure and Activity of Adenosine Deaminase
}

\author{
Davood Ajloo, ${ }^{*}$ Samaneh Hajipour, Ali Akbar Saboury, ${ }^{\dagger}$ and Saeed Zakavi ${ }^{*}$ \\ School of Chemistry, Damghan University, Damghan, Iran. E-mail: ajloo@du.ac.ir \\ Institute of Biochemistry and Biophysics, The University of Tehran, Tehran, Iran \\ $\star$ Department of Chemistry, Institute for Advanced Studies in Basic Sciences, 45195-1159, Gava Zang, Zanjan, Iran \\ Received June 14, 2011, Accepted July 29, 2011
}

\begin{abstract}
Kinetic and structural studies have been carried out on the effects of meso-tetrakis(4-sulfonatophenyl)porphyrin $\left(\mathrm{H}_{2} \mathrm{TPPS}_{4}\right)$ as an anionic and meso-tetrakis(3-N-methyl-pyridyl)porphyrin $\left(\mathrm{H}_{2} \mathrm{TMPYP}\right)$ as a cationic porphyrin with adenosine deaminase (ADA) in $25 \mathrm{mM}$ citrate/phosphate buffer, $\mathrm{pH}=4-8$, at $37^{\circ} \mathrm{C}$ using UVvis spectrophotometry, circular dichroism (CD), fluorescence spectrophotometry as well as molecular dynamics (MD) and molecular docking. Kinetic results showed that the two porphyrins are non-competitive inhibitors. Increasing $\mathrm{pH}$, increases $K_{\mathrm{I}}$ and cationic porphyrin has a higher $K_{\mathrm{I}}$ and lower binding constant $\left(K_{\mathrm{b}}\right)$ at all $\mathrm{pH}$ ranges. Analyzing the secondary structure revealed that both ligands decrease the secondary structure and that the anionic porphyrin is more effective.
\end{abstract}

Key Words : Porphyrin, Binding constant, Fluorescence, Circular dichroism, Inhibition constant

\section{Introduction}

Adenosine deaminase (ADA) is a cytosolic enzyme, which has been the object of considerable interest, mainly because a congenital defect in the enzyme causes severe combined immunodeficiency disease (SCID) in humans. ADA is an aminohydrolase (EC 3.5.4.4) which participates in the purine metabolism where it degrades either adenosine or 2'deoxyadenosine producing inosine or 2'-deoxyinosine, respectively. The enzyme is widely distributed and many of its biochemical properties have been studied in different species. ${ }^{1}$ ADA is a glycoprotein that consists of a single polypeptide chain and was sequenced in $1984 .^{2}$ The primary amino acids sequence of ADA is highly conserved across species. ${ }^{3}$ The crystal structure also revealed that ADA is a metalloenzyme that complexes one mole of $\mathrm{Zn}^{2+}$ per mole of protein. $^{4}$

The product of human ADA gene consists of 363 amino acids $(41 \mathrm{kDa})$ and there is a high degree of amino acids sequence conservation amongst species. The enzyme contains a parallel $\alpha / \beta$ barrel motif with eight central $\beta$ strands and eight peripheral $\alpha$ helices, which is a common structure found in 1/10 of all known enzymes; ${ }^{5}$ it also contains five additional helices. In humans, the highest ADA activity is found in thymus and other lymphoid tissues whereas the lowest activity can be observed in erythrocytes. ${ }^{6}$ Adenosine deaminase, an enzyme distributed in the human tissues, ${ }^{7}$ is considered a good marker of cell mediated immunity. ${ }^{8}$ It plays a crucial role in lymphocyte proliferation and differentiation, ${ }^{9}$ and shows its highest activity in T-lymphocytes. ${ }^{10}$

The human enzyme is genetically polymorphic and is found in 2 electrophoretically distinct forms termed ADA-1 and ADA-2 $2^{11}$ disorders, especially in pancreatic cancer. It may be a serum marker for the diagnosis of pancreatic cancer. ${ }^{12}$ ADA is involved in some diseases such as: tuberculosis, ${ }^{13}$ brain tumor, ${ }^{14}$ lung cancer and mesothelioma. ${ }^{15}$ In this study we have investigated the interaction between the two porphyrins and ADA.

Porphyrins, metalloporphyrins and related molecules have received a great deal of attention in recent years because they display interesting photophysical, photochemical and electrochemical properties. Porphyrins play very important roles in essential biological activities such as photosynthesis ${ }^{16}$ and participate in oxygen transport as hemoproteins. ${ }^{17}$ They were applied in many fields, such as photodynamic therapy, ${ }^{18}$ molecular wires, ${ }^{19}$ light-energy conversion, ${ }^{20}$ third-order nonlinear optical materials $\mathrm{s}^{21}$ and fluorescence switches. ${ }^{22}$ The porphyrins ability to localize into tumor cells and to photosensitize the production of singlet oxygen has led to the development of several compounds which are in use or under investigation for photodynamic therapy applications (PDT) ${ }^{23}$ Charged porphyrins are able to interact with several relevant biomolecules, i.e., nucleic acids, ${ }^{24}$ polypeptides, ${ }^{25}$ and proteins. ${ }^{26}$ A common feature of these molecules is their propensity to interact to form dimers, oligomers, or more extended aggregates. ${ }^{27}$ The extent of self aggregation can be controlled by a series of factors, including the nature of the specific porphyrin (substituent groups and coordinated metal ion) and environmental changes $(\mathrm{pH}$, ionic strength, cosolvents, temperature, etc). ${ }^{28,29}$ Porphyrins are a type of macrocyclic organic molecules which have an extensive system of delocalized $\pi$ electrons. They can be modified by connecting different peripheral substitutes, changing the central metal or expanding the size of the macrocycle.

On the other hand the structure activity relationship is vital in enzyme kinetic. Enzyme inhibition has been studied by different methods and techniques. ${ }^{30,31}$ The effect of some denaturants on the ADA structure and activity has also been 
studied. $^{32}$ The interaction of pigment with human serum albumin has been investigated by fluorescence, UV-vis spectrophotometry and calorimetery. ${ }^{33}$ In this work we investigated the effect of two anionic and cationic porphyrins on the ADA structure and activity in different $\mathrm{pH}$ ranges by fluorescence, $\mathrm{CD}$, molecular dynamics and molecular docking.

\section{Material and Methods}

Materials. Adenosine deaminase (type IV, from calf intestinal mucosa, 10102105001), were obtained from Roche. Adenosine (9-beta-di-ribofuranozil adenine, $\mathrm{C}_{10} \mathrm{H}_{13} \mathrm{~N}_{5} \mathrm{O}_{4}$, $\mathrm{MW}=267.2$, as substrate), $\mathrm{Na}_{2} \mathrm{HPO}_{4} \cdot 2 \mathrm{H}_{2} \mathrm{O}$ and citrate were purchased from Merck chemical company. Cationic $\left(\mathrm{H}_{2}\right.$ TMPYP) and anionic $\left(\mathrm{H}_{2} \mathrm{TPPS}_{4}\right)$ porphyrins were synthesized following the reported methods in the reference. ${ }^{34}$ NMR, IR and UV-vis spectroscopies of porphyrins confirm their structures (figure not shown). The structure of two porphyrins was shown in Scheme 1. The buffer solutions were prepared in doubly distilled water.

Enzyme Assay. The enzyme activity was assayed by a UV-Vis spectrophotometer model GBC 916. This was followed by a decrease in the absorbance at $265 \mathrm{~nm}$ that is due to the conversion of adenosine to inosine, based on the Kaplan method ${ }^{35}$ that used the change in extinction coefficient of $8400 \mathrm{M}^{-1} \mathrm{~cm}^{-1}$ for adenosine. The concentration of enzyme in the assay mixture was $0.94 \mathrm{nM}$. Assays were carried out in a $25 \mathrm{mM}$ citrate-phosphate buffer in the $\mathrm{pH}$ range of 4 to 8 . The activities were measured at adenosine concentration range between 7.5 to $30 \mu \mathrm{M}$. The assays were repeated at least three times. Temperature was adjusted by Lab Companion thermostat model CW-050G; $\mathrm{pH}$ was adjusted by $\mathrm{pH}$ meter Metrohm Co. model $827 \mathrm{pH}$ Lab.

Circular Dichroism Spectrophotometry. CD spectra were obtained in Far-UV spectra (190-250 nm) by an AVIV model 215 USA spectropolarimeter (displaying the CD in millidegrees ellipticity) using a cell with $1 \mathrm{~mm}$ pass length. The secondary structure of $0.2 \mathrm{mg} / \mathrm{mL}$ ADA in different $\mathrm{pH}$ in the absence and presence of $50 \mu \mathrm{M}$ of cationic and anionic porphyrins was studied. Helix, coil and beta content were obtained by analyzing the CD spectrum by CDNN software implemented in CD spectrophotometer.

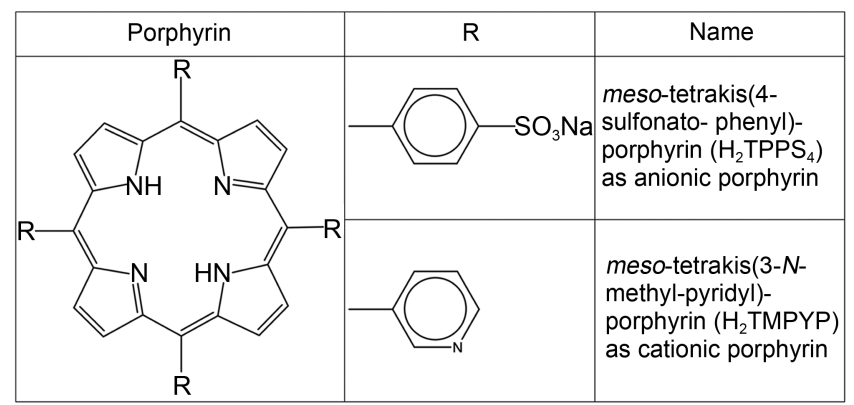

Scheme 1. Chemical structure and nomenclature of studied porphyrins.
Steady State Fluorescence Spectrophotometry. Fluorometric experiments were carried out on a Varian Cary Eclipse. Stock solutions of porphyrins $1 \mathrm{mM}$ in buffer ( $\mathrm{pH}$ range 4 to 8) were prepared at $37^{\circ} \mathrm{C}$. Various solutions of porphyrins (10 to $50 \mu \mathrm{M}$ ) were prepared from the above stock solutions by successive dilutions at $37 \mu \mathrm{C}$. The solutions of ADA $(0.72 \mu \mathrm{M})$ were prepared in $25 \mathrm{mM}$ citrate-phosphate buffer at $37^{\circ} \mathrm{C}$. The above solutions were kept in the dark and used soon after. Samples containing $200 \mu \mathrm{L}$ of the $0.72 \mu \mathrm{M}$ ADA and different concentration of porphyrin solutions were mixed to obtain the final porphyrin concentration of 10 to 50 $\mu \mathrm{M}$. The fluorescence spectra were recorded at $\lambda_{\mathrm{exc}}=295$ $\mathrm{nm}$ and $\lambda_{\mathrm{em}}$ from 300 to $400 \mathrm{~nm}$. The intensity at $336 \mathrm{~nm}$ was used to calculate the binding constant $\left(K_{\mathrm{b}}\right)$ according to literature. $^{36}$

Ligand Docking. AutoDock 3.0.5 software was used for the ligand docking to receptor. Cationic and anionic porphyrins PDB files were created in AutoDock Tools by making the necessary structural changes. Ligands PDB files were imported into ADT, polar hydrogens were added, and Gasteiger charges were computed; the rigid root and the rotatable bonds were defined by the AutoTors tool of ADT. The grid module was employed to create grid maps with 126 $\times 126 \times 126$ points and a grid-point spacing of $0.275 \mathrm{~nm}$. For each complex, 250 independent docking runs were conducted. The settings of parameters were as follows ${ }^{37}$ : population size of 50, a maximum number of 25 million energy evaluations, a maximum number of 27,000 generations, a crossover rate of 0.8 and a mutation rate of 0.02 were set up. The docking results were clustered according to a root-meansquare deviation (RMSD) criterion of $0.5 \AA$ and evaluated depending on the docking free energy.

Molecular Dynamics Simulation. All MD simulations were carried out using the GROMACS 3.3 package $^{38}$ together with the GROMOS96 force field. ${ }^{39}$ The simple point charge (SPC) model was used to describe water. ${ }^{40}$ A different time step was used to integrate the equations of motion with the Verlet algorithm. ${ }^{41}$ The long-range electrostatic interactions were treated with the particle mesh Ewald method. ${ }^{42}$ A non bond pair list cutoff of $0.9 \mathrm{~nm}$ was used. The LINCS algorithm was used to constrain all bond lengths. ${ }^{43}$

Temperatures and pressures were controlled by a NoseHoover thermostat ${ }^{44,45}$ and Parrinello-Rahman barostate ${ }^{46}$ with coupling constants of 0.1 and 0.5 , respectively. For all simulations, the atomic coordinates were saved every $50 \mathrm{ps}$ for analysis. MD simulations were run on a 40-CPU clustered Rocks network.

The starting structure of ADA was constructed based on the X-ray crystal structure of ADA (PDB code 1VFL). The resulting system of $\mathrm{MD}$ models contains a protein, about 14,000 water molecules in a box dimension of $8 \mathrm{~nm} \times 8 \mathrm{~nm}$ $\times 8 \mathrm{~nm}$. The force field of ligands was generated using the PRODRG web server. ${ }^{47}$ Then, porphyrin ions were randomly distributed around the ADA. The initial configurations of the ADA, porphyrin and water were equilibrated.

In order to simulate lower $\mathrm{pHs}$ (acidic form), all carboxyl groups (COO-) were protonated and converted to $\mathrm{COOH}$ by 
definite tools implemented in GROMACS. In addition, at higher $\mathrm{pHs}$ (alkaline form), $\mathrm{NH}_{3}{ }^{+}$was converted to $\mathrm{NH}_{2}$. At neutral $\mathrm{pH}$, we used the crystal structure ( $\mathrm{pdb}$ code; 1VFL) downloaded from the protein data bank (model 1). At the first, the structures of all three forms were optimized in the 20 ns time duration in the absence of ligand (model 2). Variations of RMSD, $\mathrm{CD}_{222 \mathrm{~nm}}$, helix, beta, coil and RDF were analyzed using topology and trajectory files by the VADAR software. ${ }^{48}$ Then docking was performed on the optimized acidic, neutral and alkaline forms of ADA after 20 ns. After that, MD calculations were performed separately in $30 \mathrm{~ns}$ for the optimized neutral forms only (model 3 ) in the presence of 13 molecules of porphyrin, so that ratio of porphyrin to ADA was 13 in $\mathrm{MD}$, and 1-10 in $\mathrm{CD}$ as wells as 10-50 in fluorescence. Finally, RMSD, RDF, $\mathrm{CD}_{222 \mathrm{~nm}}$, helix, coil and beta content were also calculated.

\section{Results and Discussion}

Enzyme Kinetics. Figure 1 shows the Lineweaver-Burk plot $(1 / \mathrm{V}$ versus $1 /[\mathrm{S}])$ for the conversion of adenosine to inosine by adenosine deaminase (ADA) in the absence and presence of cationic (a-e) and anionic (f-j) porphyrins at physiological temperature $\left(37^{\circ} \mathrm{C}\right)$ and different $\mathrm{pH}$ ranges. In the absence of porphyrins, decreasing the $\mathrm{pH}$ make decreasing the enzyme activity. The shape of the curves shows that the mode of inhibition is non-competitive. The slope of these curves was plotted versus ligand concentration [I] according to following equations ${ }^{49}$ :

$$
\begin{gathered}
\frac{1}{V}=\frac{K_{m}}{V_{\max }}\left(1+\frac{[I]}{K_{I}}\right) \frac{1}{[S]}+\frac{1}{V_{\max }}\left(1+\frac{[I]}{K_{I}}\right) \\
\text { Slope }=\frac{K_{m}}{V_{\max }}\left(1+\frac{[I]}{K_{I}}\right)=\frac{K_{m}}{V_{\max }}+\frac{K_{m}}{V_{\max }} \frac{[I]}{K_{I}} \\
K_{\text {m,app }}=K_{m}{ }^{\prime}=K_{m}\left(1+\frac{[I]}{K_{I}}\right)
\end{gathered}
$$

Parts $k$ and $l$ of Figure 1 plotted the slope of the above equation versus [I] (secondary plot) at $\mathrm{pH} 4$ in the presence of cationic and anionic porphyrins as a sample plot. The secondary plot has an intercept of $K_{\mathrm{m}} / V_{\max }$ and slope of $K_{\mathrm{m}} / V_{\max } K_{\mathrm{I}}$. The inhibition constants which were obtained from the division of the intercept by the slope of the secondary plot have been listed in Table 1 . Increasing the $\mathrm{pH}$ enhances the inhibition constant $\left(K_{\mathrm{I}}\right)$ for both ligands. The
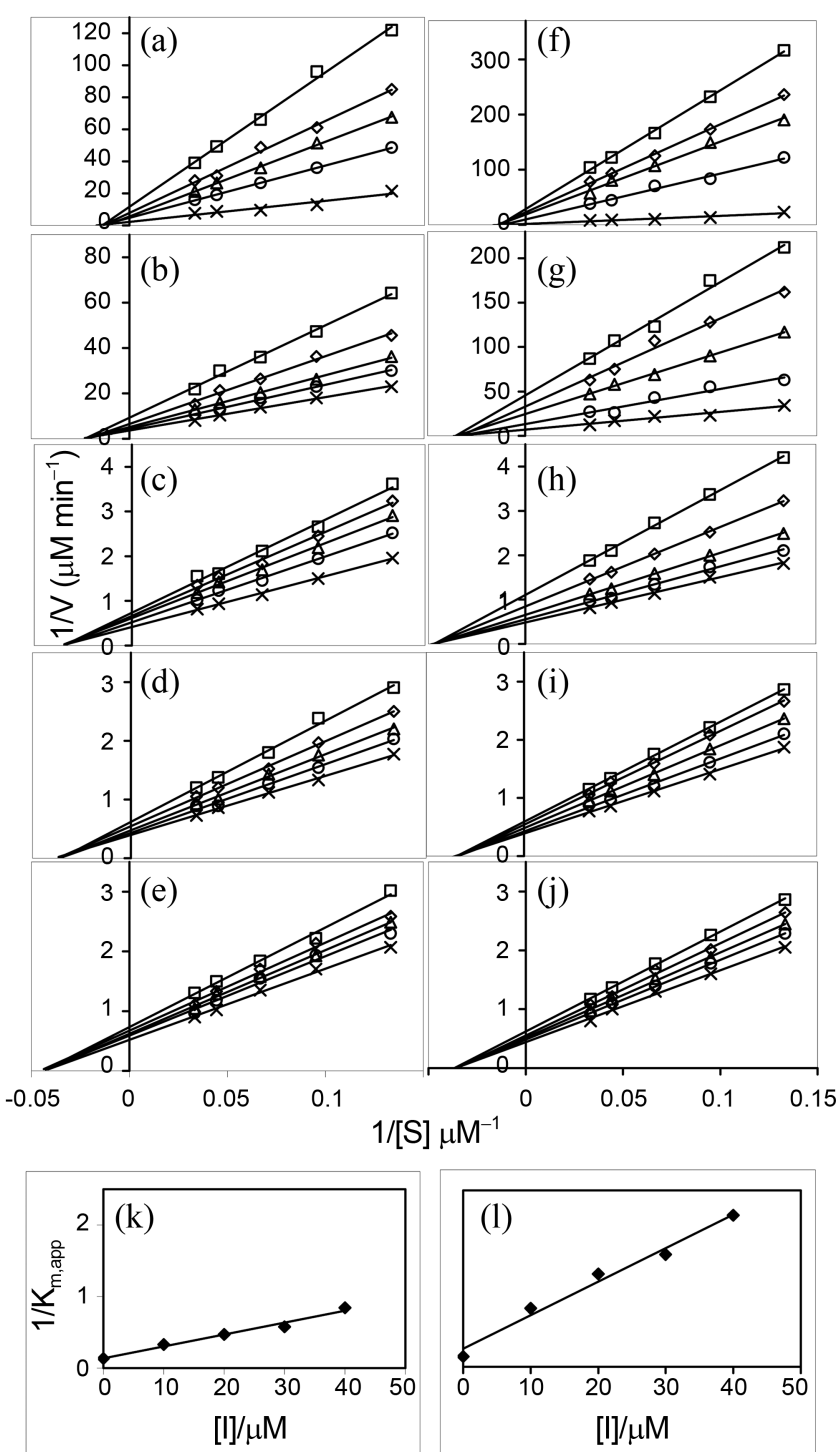

Figure 1. Lineweaver-Burk plots for kinetics of $0.94 \mathrm{nM}$ ADA in the absence $(\times)$ and presence of $10(O), 20(\triangle), 30(\diamond), 40(\square)$ $\mathrm{mM}$ of cationic porphyrin at pH 4 (a) 5 (b) 6 (c) 7 (d) and 8 (e) and anionic porphyrin at $\mathrm{pH} 4$ (f) 5 (g) 6 (h) 7 (i) and 8 (j). Secondary plots for ADA at $\mathrm{pH} 4$ in the presence of cationic $(\mathrm{k})$ and anionic (l) porphyrins.

cationic ligand has a higher $K_{\mathrm{I}}$ compared to its anionic counterpart and consequently the binding constant $\left(K_{\mathrm{b}}=1 / K_{\mathrm{I}}\right)$ is higher for the anionic ligand.

Table 1. Inhibition constant $\left(K_{\mathrm{I}}\right.$ in $\left.\mu \mathrm{M}\right)$, binding constant $\left(K_{\mathrm{b}}\right.$ in $\left.\mathrm{M}^{-1}\right)$, binding free energy $\left(\Delta G_{\mathrm{b}}\right.$ in $\left.\mathrm{kcal} / \mathrm{mol}\right)$ and heterogeneity constant $(n)$ for anionic and cationic porphyrin at different $\mathrm{pH}$ ranges obtained from enzyme kinetic and fluorescence spectrophotometry

\begin{tabular}{ccccccccc}
\hline & \multicolumn{2}{c}{$K_{\mathrm{I}}$} & \multicolumn{2}{c}{$K_{\mathrm{b}} \times 10^{-6}$} & \multicolumn{2}{c}{$\Delta G_{\mathrm{b}}$} & \multicolumn{2}{c}{$n$} \\
\hline $\mathrm{pH}$ & cationic & anionic & cationic & anionic & cationic & anionic & cationic & anionic \\
\hline 4 & 13.0 & 11.0 & $5.94( \pm 0.06)^{b}$ & $7.94( \pm 0.71)$ & -9.20 & -9.37 & $1.15( \pm 0.16)$ & $1.28( \pm 0.19)$ \\
5 & 31.3 & 16.2 & $3.12( \pm 0.05)$ & $5.77( \pm 0.51)$ & -8.82 & -9.18 & $1.48( \pm 0.29)$ & $1.36( \pm 0.12)$ \\
6 & 36.6 & 18.2 & $1.39( \pm 0.18)$ & $3.22( \pm 0.17)$ & -8.35 & -8.84 & $1.28( \pm 0.16)$ & $1.29( \pm 0.22)$ \\
7 & 45.0 & 40.1 & $0.38( \pm 0.05)$ & $\mathrm{N}^{a}$ & -7.58 & & $1.76( \pm 0.13)$ & $\mathrm{N}$ \\
8 & 132.2 & 118.0 & $0.19( \pm 0.01)$ & $\mathrm{N}$ & -7.17 & & $1.22( \pm 0.23)$ & $\mathrm{N}$ \\
\hline
\end{tabular}

${ }^{a} \mathrm{~N}$ : was not determined due to limitation in quenching. ${ }^{b}$ Standard errors were determined by SPSS software. 
Fluorescence Spectra and Binding Constants for Porphyrin-ADA Complexes. Binding of the anionic and cationic porphyrins to ADA was investigated by fluorescence spectrophotometry. The ligand was added to the $200 \mu \mathrm{L}$ of $7.2 \times$ $10^{-7} \mathrm{M}$ of $\mathrm{ADA}$ at $37^{\circ} \mathrm{C}$ so that the ligand concentration changed from 0 to $50 \mathrm{mM}$. Figure 2 shows the effect of porphyrins on the fluorescence spectra. Both ligands decrease the fluorescence intensity and quench the tryptophan fluorescence emissions. Therefore we consider the ADA tryptophans.

ADA is a single polypeptide containing four tryptophans; Trp117, Trp161, Trp264 and Trp272. When the molecules interact with ADA, tryptophan fluorescence may change depending on the impact of such interaction on the protein conformation, or via direct quenching effect. On the assumption that there are $(n)$ substantive binding sites for quencher $(Q)$ on enzyme $(E)$, the quenching reaction can be shown as follows: ${ }^{36}$

$$
\begin{gathered}
n Q+E \leftrightarrow Q_{n} E \\
\log \left[\left(F_{o}-F\right) / F_{o}\right]=\log K_{A}+n \log [Q]
\end{gathered}
$$

The decrease of fluorescence intensity for ADA has been monitored at $336 \mathrm{~nm}$ for ADA-porphyrin systems. Figure 2 shows representative results for each system. The plot of log $\left[\left(F_{0}-F\right) / F_{\mathrm{o}}\right]$ versus $\log [Q]$ is shown in the inset of Figure 2 . The values of binding constant $\left(K_{\mathrm{b}}\right)$ and heterogeneity constant $(n)$ can be obtained from the intercept and slope of equation (3). We assumed that the observed changes in fluorescence come from the interaction between porphyrin and HSA, so the quenching constant can be taken as the binding constant of the complex formation. The calculated association constants for the porphyrin-ADA suggest low affinity porphyrin-ADA binding, compared to the other strong ligand-protein complexes. ${ }^{36}$ Lower binding constants $\left(10^{4}\right.$ to $\left.10^{5} \mathrm{M}^{-1}\right)$ were also reported for several other ligandprotein complexes using fluorescence spectroscopic methods [see Ref. 36 and references there in].

Table 1 has also listed the inhibition constant $\left(K_{\mathrm{I}}\right)$, binding constant $\left(K_{\mathrm{b}}\right)$ and free energy of binding $\left(\Delta G_{\mathrm{b}}\right)$. It shows that the binding affinity of anionic porphyrin at low $\mathrm{pH}$ is higher than that of the cationic one. Increasing the $\mathrm{pH}$ for cationic porphyrin increases the binding affinity. The affinity values were not determined for ADA in the presence of anionic at higher $\mathrm{pH}$, because quenching was not observed and differences in fluorescence intensity didn't change. Effect of $\mathrm{pH}$

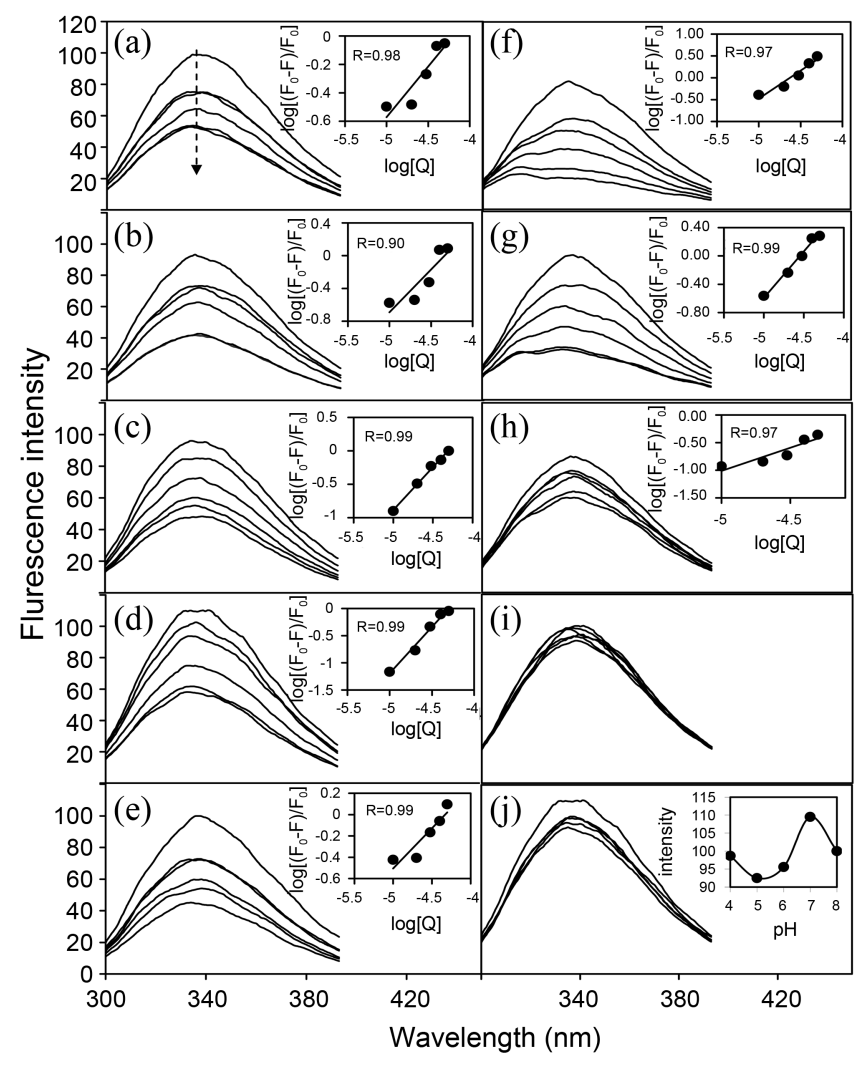

Figure 2. Variation of fluorescence emission spectra in the presence of cationic porphyrin at $\mathrm{pH}$ 4-8 (a-e) and anionic porphyrin at $\mathrm{pH}$ 4-7 (f-i). Inset of figures a-h show the variation of $\log \left[\left(F_{0}-F\right) / F\right]$ against $\log [Q]$ using equation (3). (j) Variation of fluorescence spectra and maximum intensity (inset of $\mathrm{j}$ ) in the absence of porphyrin in different $\mathrm{pH}$ ranges.

on the fluorescence intensity was also shown in Figure 2(j). The $n$ values were also determined from the slope of Figure 2 that fluctuates around unit. It shows that about one molecule of ligand binds to the one molecule of enzyme.

CD Results. CD spectra of $0.2 \mathrm{mg} / \mathrm{mL}$ ADA in citratephosphate buffer at $\mathrm{pH}$ ranges of 4 to 8 in the absence and presence of $50 \mu \mathrm{M}$ of anionic and cationic porphyrins are shown in Figure 3. It shows that decreasing the $\mathrm{pH}$ from 7 to 4 makes a decrease in the secondary structure. Increasing $\mathrm{pH}$ form 7 to 8 , decreases the secondary structure again, so that, ADA has higher secondary structure at $\mathrm{pH}$ 7. On the other hand, Figure 3(b) shows that both ligands decrease the secondary structure and anionic ligand has more effect. Detailed information about the protein structure such as

Table 2. Results of secondary structure (in percentage) obtained from CDNN software implemented in CD spectrophotometer at different $\mathrm{pH}$ ranges in the absence and presence of cationic and anionic porphyrins

\begin{tabular}{lccccc|cc|cc}
\hline & \multicolumn{4}{c}{ No ligand } & \multicolumn{3}{c}{ cationic ligand } & \multicolumn{2}{c}{ anionic ligand } \\
\hline $\mathrm{pH}$ & 4 & 5 & 6 & 7 & 8 & 4 & 7 & 4 & 7 \\
\hline Helix & 18.12 & 19.45 & 20.45 & 27.51 & 25.82 & 19.68 & 22.78 & 18.00 & 19.36 \\
Antiparallel & 12.13 & 11.02 & 10.94 & 9.20 & 9.58 & 11.22 & 10.34 & 11.48 & 11.14 \\
Parallel & 13.25 & 12.24 & 11.84 & 10.15 & 10.52 & 12.11 & 11.25 & 12.61 & 12.20 \\
Beta-Turn & 16.51 & 16.64 & 16.86 & 16.51 & 16.62 & 16.83 & 16.74 & 16.70 & 16.71 \\
Random coil & 41.23 & 40.76 & 39.91 & 36.72 & 37.46 & 40.25 & 38.88 & 41.13 & 40.58 \\
\hline
\end{tabular}




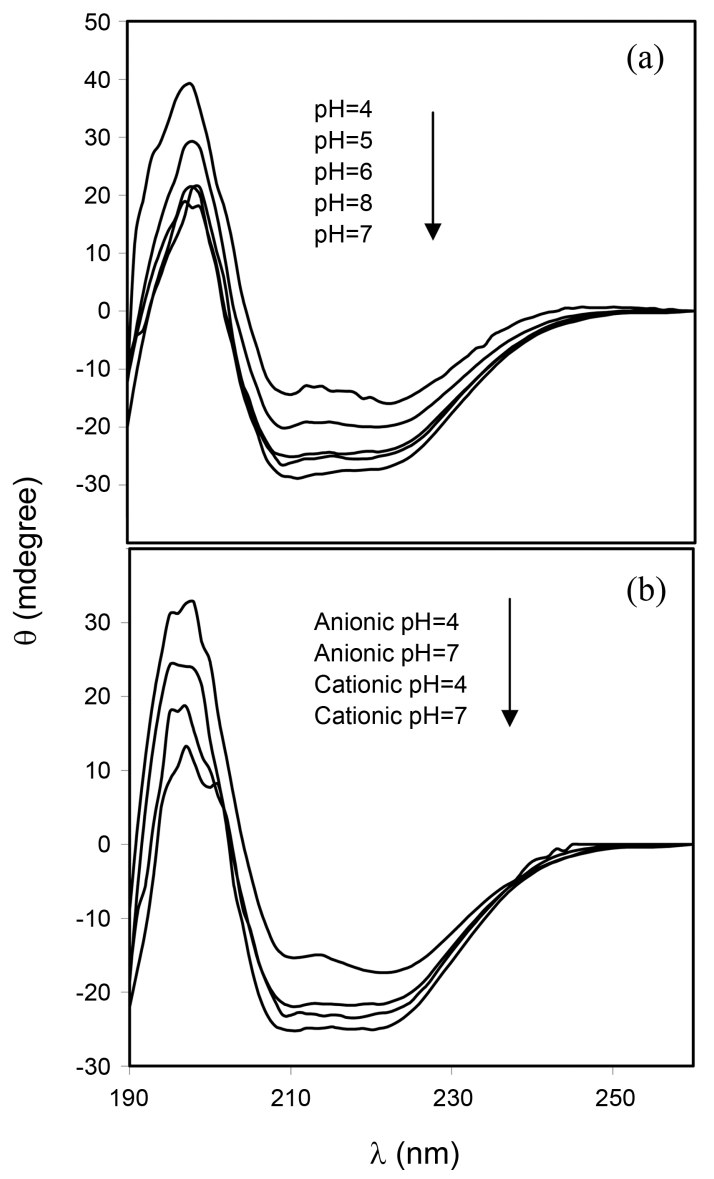

Figure 3. $\mathrm{CD}$ spectra for $0.2 \mathrm{mg} / \mathrm{mL}$ ADA in $25 \mathrm{mM}$ citratephosphate buffer (a) in the absence of porphyrin at $\mathrm{pH}=4,5,7,6$ and 8 (from up to down). (b) ADA in the presence of anionic porphyrin at $\mathrm{pH}=4$ and 7 , cationic porphyrin at $\mathrm{pH}=4$ and 7 (from up to down).

helix, coil and beta are listed in Table 2. By increasing $\mathrm{pH}$, the helix percentage increases and coil, parallel and antiparallel decrease while the turn doesn't change significantly.

\section{Molecular Dynamics Simulation.}

Effect of $\mathbf{p H}$ : MD process was performed on the ADA in the $20 \mathrm{~ns}$ time interval in three acidic, neutral and basic conditions by GROMACS molecular dynamics (model 2). The results show that the acidic form has a higher surface area and coil percentage relative to others. The variation of surface area in $20 \mathrm{~ns}$ time evolution was not significant (data not shown).

Effect of Ligand: The structure of neutral ADA which has been optimized during $20 \mathrm{~ns}$ (model 2) was optimized separately in the presence of 13 molecules of anionic and cationic porphyrins in a period of $30 \mathrm{~ns}$ (model 3). Figure 4(a) and (b) show the starting point of the MD simulation for both porphyrins. The software automatically distributes ligands around the ADA. The final structure, after $30 \mathrm{~ns}$, is shown in Figure 4(c) and d. It shows that ligands tend to relocate to the specific site. The expended part of the binding site in Figure 4(c) and (d) are shown in Figure 4(e) and f. It shows that both ligands prefer to move near the Trp264 and Trp272.

Different structural samples in different time scales were extracted from the trajectory file and entered into VADAR. ${ }^{48}$ This web server calculates helix, coil, turn and beta percents for each sample. Figure 5 shows the variation of helix, coil, beta and turn for ADA in the presence of anionic and cationic porphyrins.

Figure 5(a) shows the root mean square deviation (RMSD) of the ADA in the $30 \mathrm{~ns}$ time interval. It shows that the system reaches a stable state after about $10 \mathrm{~ns}$. The figure also shows that ADA has more structural changes (RMSD) in the presence of anionic ligands than in the presence of cationic ligands. Figure 5(b) shows the helicity as $\mathrm{CD}_{222 \mathrm{~nm}}$ which decreases in the anionic case and does not change significantly in the cationic form. Figures 5(c) and (d) show variations of helix and coil contents related to ADA. Both ligands decrease the helix and increase the coil. These variations are higher in the anionic case. Figure 5(e) and (f) show variation of beta and turn content. These values are higher in the cationic form and the trend of turn content is decreasing while beta doesn't change much. Radial distribution function (RDF) is a criterion for the distribution of atoms, molecules or other species around a target specie.

Table 4. Free energy in $\mathrm{kcal} / \mathrm{mol}$ for the first cluster rank related to the docking of anionic and cationic porphyrins to ADA in three forms $\left(\Delta G_{\mathrm{doc}}\right)$

\begin{tabular}{lccc}
\hline & Acidic & Neutral & Basic \\
\hline Porphyrin & \multicolumn{3}{c}{ whole enzyme } \\
\hline anionic & -11.99 & -12.31 & -8.86 \\
cationic & -12.97 & -14.72 & -13.30 \\
\hline \multicolumn{3}{c}{ enzyme active site } \\
\hline anionic & -10.72 & -8.64 & -6.07 \\
cationic & -13.74 & -12.63 & -10.80 \\
\hline
\end{tabular}

Table 3. Structural parameters calculated by molecular dynamics and VADAR in different models

\begin{tabular}{|c|c|c|c|c|c|}
\hline Model & Sample & Helix\% & Beta $\%$ & Coil\% & Turn $\%$ \\
\hline 1 & Crystal structure (1VFL) & 48 & 17 & 33 & 19 \\
\hline \multirow{3}{*}{2} & Optimized acidic after $20 \mathrm{~ns}$ & 13 & 17 & 68 & 6 \\
\hline & Optimized neutral $r$ after $20 \mathrm{~ns}$ & 27 & 15 & 56 & 10 \\
\hline & Optimized basic after $20 \mathrm{~ns}$ & 33 & 18 & 47 & 14 \\
\hline \multirow{2}{*}{3} & Optimized neutral form of model 2 in the presence of anionic porphyrin after $30 \mathrm{~ns}$ & 14 & 10 & 75 & 9 \\
\hline & Optimized neutral form of model 2 in the presence of cationic porphyrin after $30 \mathrm{~ns}$ & 16 & 15 & 67 & 13 \\
\hline
\end{tabular}


(a)

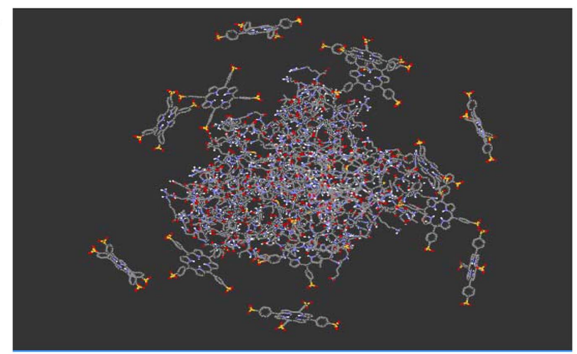

(c)

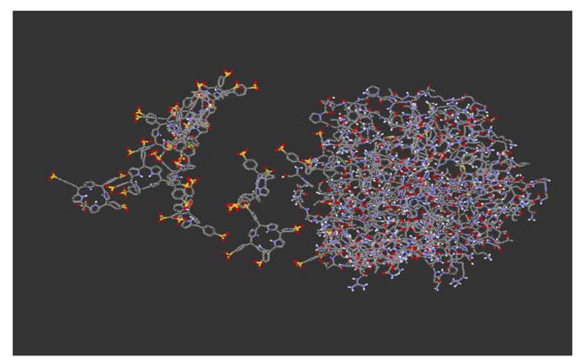

(e)

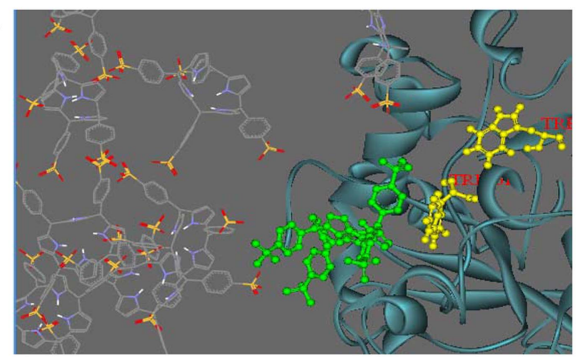

(b)

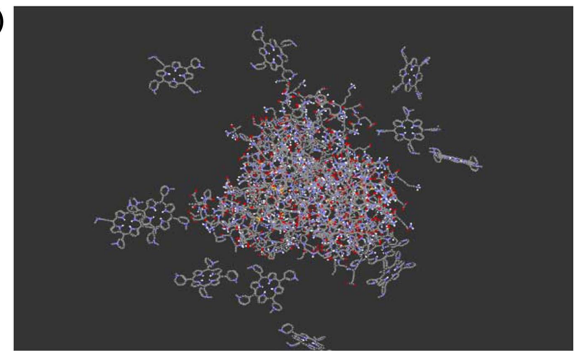

(d)

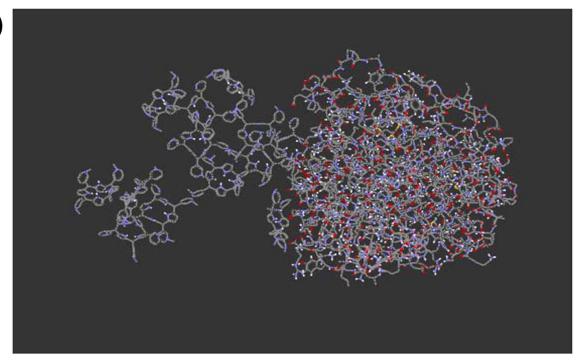

(f)

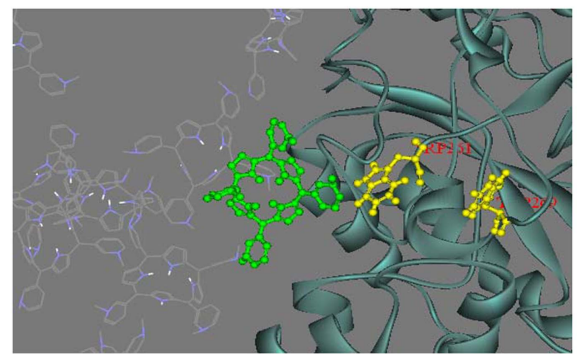

Figure 4. Structure of ADA at the initial time of $30 \mathrm{~ns}$ MD in the presence of 13 molecules of (a) anionic, (b) cationic porphyrins and final time for (c) anionic, (d) cationic porphyrins. Parts (e) and (f) show expended structures of part (c) and (d), respectively. Green color denotes the most nearest ligand to Trp263 and Trp272 (yellow color). Red, orange, grey, white and blue colors represent the oxygen, sulfur, hydrogen, carbon and nitrogen, respectively.

The distribution of porphyrins around ADA is shown in Figure $5(\mathrm{~g})$ and it can be seen that it is higher for the cationic porphyrin. In addition the distribution of porphyrins around the other porphyrins is shown in Figure 5(h). In this case the cationic has a higher value than the anionic. So it is clear that the cationic has a higher affinity for binding to ADA and also to other cationic porphyrins.

The 3D-structure of ADA at the just final time scale was extracted from the trajectory file and the helix, coil and beta percentage were calculated by VADAR. Table 5 has summarized the cited parameters for three models. It has been shown that both ligands decrease the helix and increases the coil. This proves that the ADA structure has been slightly unfolded and its amino acids have become more accessible to the solvent. The trend for the helix percentage is as follows: model $1>\operatorname{model} 2>\operatorname{model} 3$. Thus optimization in the absence and presence of ligands decreases the helix percentage. On the other hand, the decrease of the secondary structure is higher in the anionic form which is compatible with the CD data.

\section{Docking Results.}

Ligand-protein Interaction: The interaction between ligand and enzyme was investigated by AutoDock 3.0.5. Docking was performed on the three optimized acidic, neutral and basic forms (model 2). All 250 runs were collected while some were only located in a single binding site and so produced just one cluster. Docking results show that, each cationic and anionic porphyrin bind to a different site having different free energies of docking. We selected the grid box in two different sizes. In one of them, the box surrounded the whole of the enzyme while in the second; it only surrounded the active site. The free energy of docking was calculated and sorted so that the highest negative free energy appeared in the first rank. In order to compare the different ligands in different conditions, we only considered the free energy of the first rank (Table 4). When we look at the results for the whole enzyme, the trend of docking free energy in both ligands in different states is neutral $<$ acidic $<$ basic. Cited values are more negative for cationic than for anionic. When we consider only the active site, the cited trend is acidic $<$ neutral $<$ basic and the cationic is also more negative than the anionic. This last trend seems to be more logical because it is more compatible with the experimental results (Table 1).

Figure 6(a) shows the position of four tryptophans in different sites of ADA. Figure 6(b) shows all distributions for the 250 runs corresponding to anionic porphyrin around the neutral ADA as a sample figure. Figure 6(c) shows the binding sites for a few of the most negative clusters near the ADA tryptophans. These clusters are near the Trp117 and Trp161 and specially, the surface of porphyrin is parallel to 

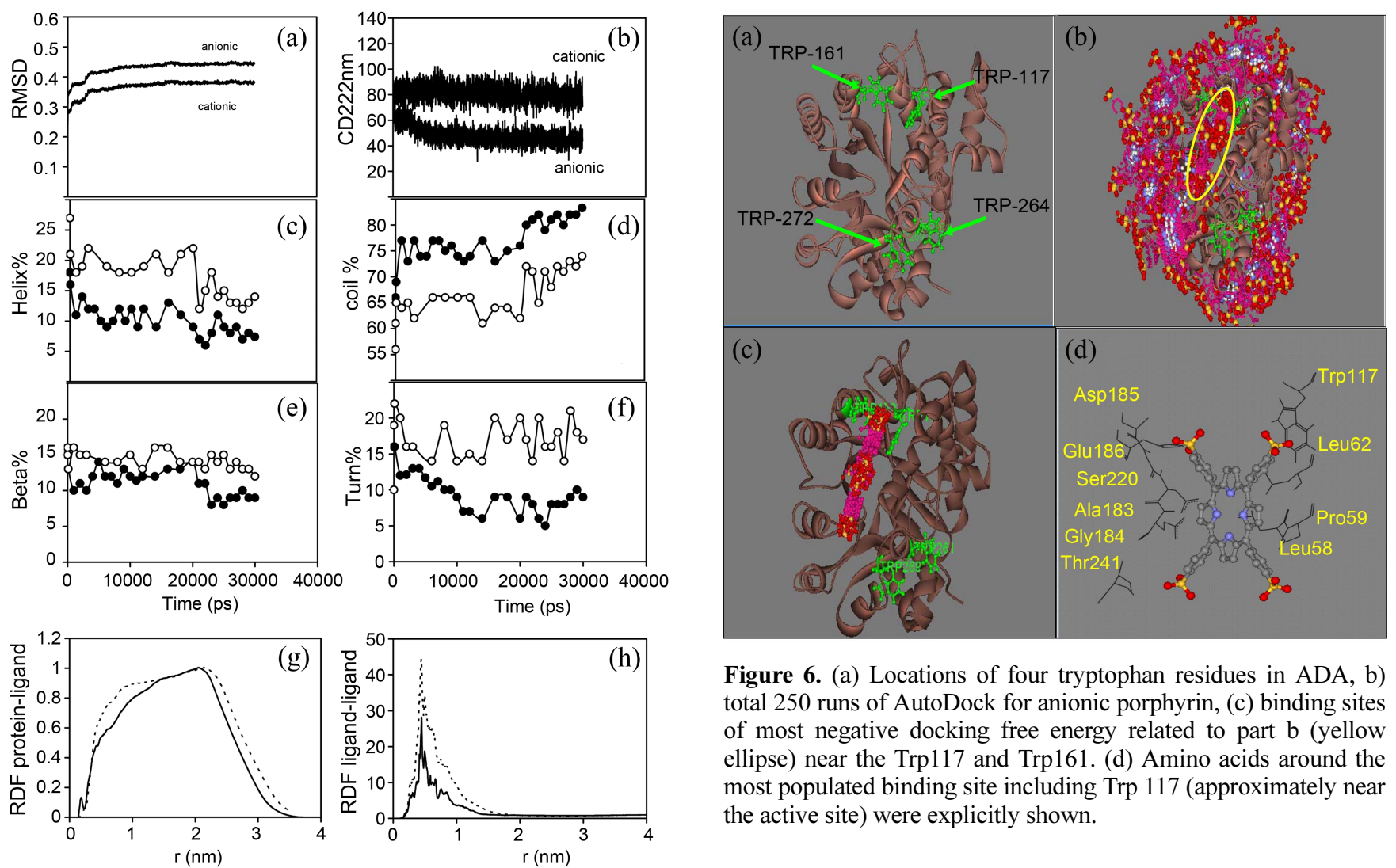

Figure 5. Calculated (a) RMSD, (b) $\mathrm{CD}_{222 \mathrm{~nm}}$, (c) helix, (d) coil, (e) beta (f) turn percentages, (g) RDF of protein-porphyrin and (h) RDF of porphyrin-porphyrin by molecular dynamics for ADA in the neutral form in the presence of 13 molecules of anionic and cationic porphyrins. Cationic (Open circle in c-f and dashed line in $\mathrm{g}-\mathrm{h}$ ) anionic (filled circle in c-f and solid line in $\mathrm{g}-\mathrm{h}$ ).

the surface of Trp117. The distribution of porphyrins around the Trp117 and Trp161 of acidic and neutral forms of ADA are higher than the basic form (figures not shown). Figure 6(d) explicitly shows the amino acids around the most populated binding site. This site includes Trp 117 and has approximately located near the active site. The same results also obtained for cationic porphyrin (data not shown).

On the other hand, electrostatic surfaces correspond to the most negative docking sites (first negative rank) for interaction of cationic and anionic porphyrins with ADA were

Figure 6. (a) Locations of four tryptophan residues in ADA, b) total 250 runs of AutoDock for anionic porphyrin, (c) binding sites of most negative docking free energy related to part $b$ (yellow ellipse) near the Trp117 and Trp161. (d) Amino acids around the most populated binding site including Trp 117 (approximately near the active site) were explicitly shown.

shown in Figure 7. Amino acid residues were explicitly shown for cationic and anionic porphyrins, so that the red color represents the negative charge and blue color represents the positive charges, respectively. As we see in this figure, red color surfaces (representative of negative charges) are higher in the cationic porphyrin (Fig. 7(a)) while the blue color (representative of negative charges) are higher in anionic porphyrin (Fig. 7(b)). Figure 7(c) and (d) show the amino acids belong to most negative docking sites that are different for cationic and anionic poprphyrins.

Using the DS Visualizer software, the number of runs in which porphyrins locates near each tryptophan (NPNT) and the related docking free energy for the three forms of ADA has been listed in Table 5. It shows that the number of porphyrins around Trp117 is higher than the others in both anionic and cationic porphyrin. The average free energy of docking in the last row of Table 5 shows that the trend of

Table 5. Docking free energy (in $\mathrm{kcal} / \mathrm{mol}$ ) of two porphyrins near the four tryptophans

\begin{tabular}{ccccccccccccc}
\hline & \multicolumn{4}{c}{ Acidic } & \multicolumn{3}{c}{ Neutral } & \multicolumn{2}{c}{ Basic } \\
\hline \multicolumn{4}{c}{ Anionic } & \multicolumn{2}{c}{ Cationic } & \multicolumn{2}{c}{ Anionic } & \multicolumn{2}{c}{ Cationic } & \multicolumn{2}{c}{ Anionic } & \multicolumn{2}{c}{ Cationic } \\
\hline & NPNT $^{a}$ & $\Delta G_{\text {doc }}^{b}$ & NPNT & $\Delta G_{\text {doc }}$ & NPNT & $\Delta G_{\text {doc }}$ & NPNT & $\Delta G_{\text {doc }}$ & NPNT & $\Delta G_{\text {doc }}$ & NPNT & $\Delta G_{\text {doc }}$ \\
\hline Trp117 & 90 & -852.52 & 31 & -358.24 & 49 & -469.03 & 47 & -557.16 & 12 & -71.39 & 8 & -77.69 \\
Trp161 & 0 & 0 & 25 & -298.79 & 0 & 0 & 4 & -43.6 & 10 & -61.82 & 7 & -69.77 \\
Trp264 & 1 & -7.99 & 10 & -107.27 & 0 & 0 & 1 & -8.91 & 11 & -68.99 & 22 & -240.37 \\
Trp272 & 0 & 0 & 11 & -118.84 & 5 & -38.09 & 3 & -28.73 & 1 & -6.41 & 6 & -60.27 \\
Sum & 91 & -860.51 & 77 & -883.14 & 54 & -507.12 & 55 & -638.40 & 34 & -208.60 & 43 & -448.10 \\
Average & & -9.45 & & -11.47 & & -9.39 & & -11.61 & & -6.13 & -10.42 \\
\hline
\end{tabular}

${ }^{a}$ NPNT is the number of runs among 250 runs that porphyrins locate close to the related tryptophan. ${ }^{b} \Delta \mathrm{G}_{\mathrm{doc}}$ is the free energy of docking 


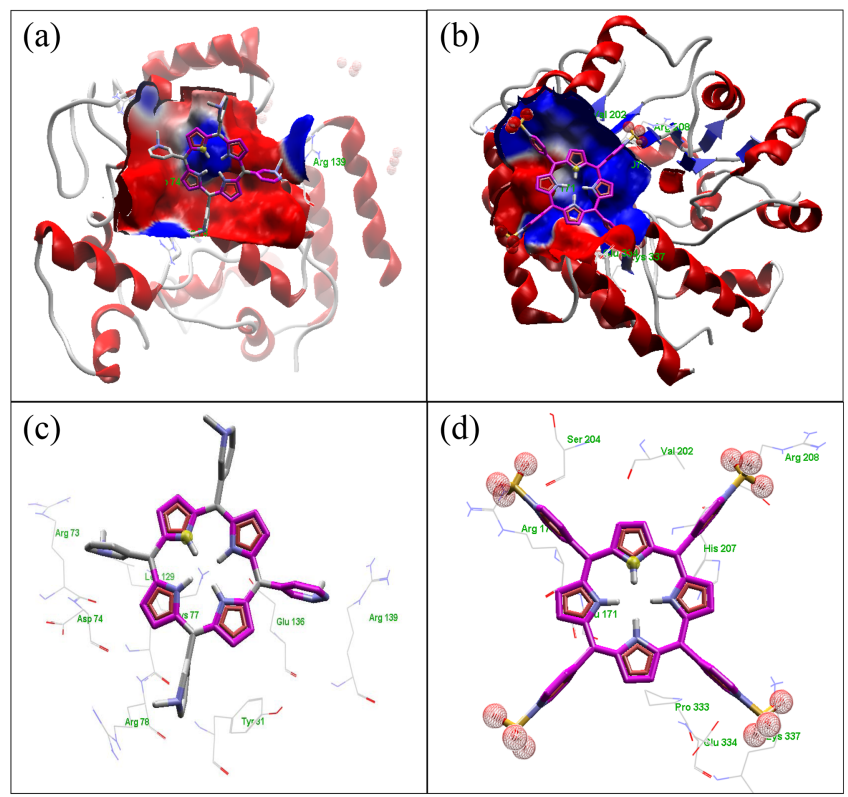

Figure 7. Electrostatic surfaces correspond to the most negative docking sites (first negative rank) for interaction of cationic (a) and anionic porphyrins (b) with ADA. Amino acid residues were explicitly shown for cationic (c) and anionic porphyrins (d). Red and blue colors represent the negative and positive charges, respectively.
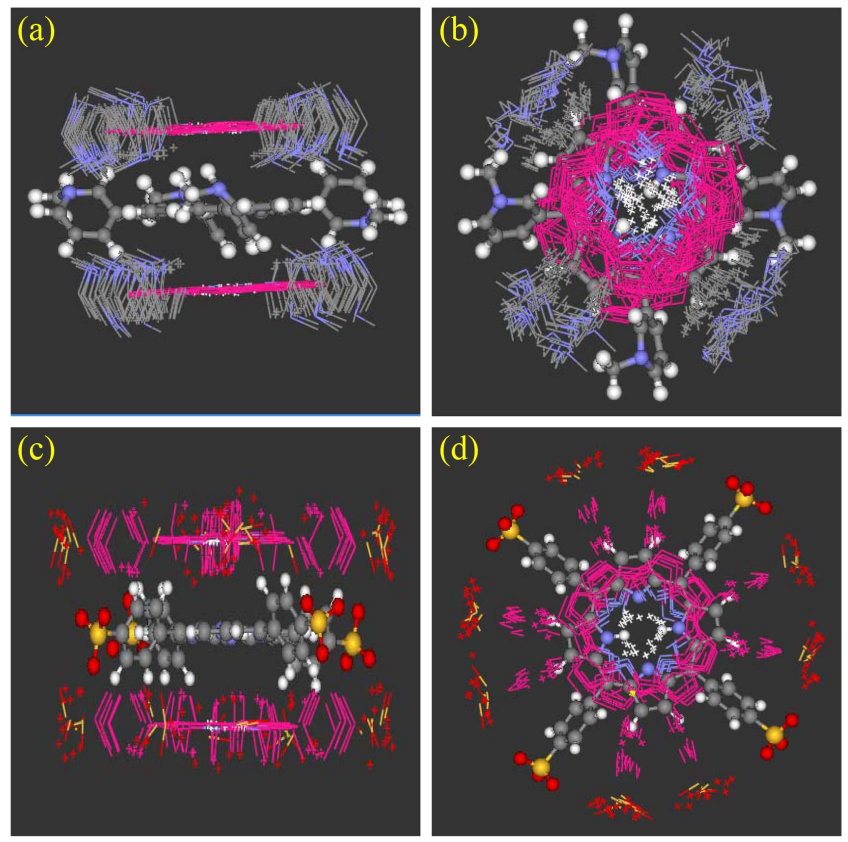

Figure 8. Streoview plot of (a) cationic-cationic interaction in horizontal, (b) vertical view and (c) anionic-anionic interaction in horizontal (d) in vertical view obtained from Autodock data and drawn by DS Visualizer.

docking free energy of anionic to ADA is; acidic ADA < neutral ADA $<$ basic ADA and for cationic is neutral ADA $<$ acidic ADA $<$ basic ADA. Finally the free energy of docking of cationic to ADA is more negative than cationic.

At higher $\mathrm{pH}$, the anionic porphyrin has less affinity to ADA due to the repulsion of negative charges. This may decreases the interaction of porphyrin and tryptophan. On
Table 6. Dimerization free energy $\left(\Delta G_{\mathrm{dim}}\right)$ in $\mathrm{kcal} / \mathrm{mol}$ for anionic and cationic porphyrins calculated by AutoDock

\begin{tabular}{cccccc}
\hline \multicolumn{3}{c}{$\mathrm{H}_{2}$ TMPYP (cationic) } & \multicolumn{3}{c}{$\mathrm{H}_{2} \mathrm{TPPS}_{4}$ (anionic) } \\
\hline $\begin{array}{c}\text { Cluster } \\
\text { rank }\end{array}$ & $\begin{array}{c}\text { Lowest } \\
\text { docked } \\
\text { energy }\end{array}$ & $\begin{array}{c}\text { Number of } \\
\text { runs in a } \\
\text { cluster }\end{array}$ & $\begin{array}{c}\text { Cluster } \\
\text { Rank }\end{array}$ & $\begin{array}{c}\text { Lowest } \\
\text { docked } \\
\text { energy }\end{array}$ & $\begin{array}{c}\text { Number of } \\
\text { runs in a } \\
\text { cluster }\end{array}$ \\
\hline 1 & -11.10 & 33 & 1 & -4.46 & 81 \\
2 & -10.94 & 8 & 2 & -4.42 & 21 \\
3 & -10.90 & 1 & 3 & -4.41 & 8 \\
4 & -10.87 & 3 & 4 & -4.39 & 46 \\
5 & -10.87 & 1 & 5 & -4.38 & 17 \\
6 & -10.84 & 23 & 6 & -4.37 & 2 \\
7 & -10.83 & 4 & 7 & -4.34 & 7 \\
8 & -10.78 & 3 & 8 & -4.33 & 4 \\
9 & -10.77 & 17 & 9 & -4.31 & 9 \\
10 & -10.75 & 1 & 10 & -4.30 & 2 \\
11 & -10.74 & 1 & 11 & -4.28 & 1 \\
12 & -10.72 & 5 & 12 & -4.25 & 1 \\
13 & -10.72 & 32 & 13 & -4.22 & 1 \\
\hline
\end{tabular}

Table 7. Comparison between the docking and dimerization free energy for cationic and anionic ligands obtained by equation (4)

\begin{tabular}{ccccc}
\hline & \multicolumn{3}{c}{$\Delta G_{\text {doc }}$} & $\Delta G_{\text {dim }}$ \\
\cline { 2 - 5 } & Acidic & Neutral & Basic & \\
\hline Anionic & -9.45 & -9.39 & -6.13 & -4.46 \\
Cationic & -11.46 & -11.6 & -10.42 & -11.1 \\
$\Delta \Delta G$ & $\mathbf{- 4 . 6 3}$ & $\mathbf{- 4 . 4 3}$ & $\mathbf{- 2 . 3 5}$ & \\
\hline
\end{tabular}

the other hand, fluorescence results also support this phenomenon, because Figure 2(i) shows that at higher $\mathrm{pH}$ quenching dose not occur.

Ligand-ligand Interaction: The trends of binding in the cationic and anionic porphyrins are different from those of experimental results. Anionic porphyrin has more affinity for binding to $\mathrm{ADA}$ in the experimental results, because it has less $K_{\mathrm{I}}\left(1 / K_{\mathrm{b}}\right)$ in enzyme kinetics and higher $K_{\mathrm{b}}$ in fluorescence studies. While in the docking results, the cationic porphyrin has more affinity (less $\mathrm{D} G_{\mathrm{doc}}$ ) to ADA. In order to remove this problem, we firstly considered the energy of porphyrin dimerization. Dimerization or interaction energy was obtained by AutoDock in the same way as docking energy. In this case, one porphyrin was considered as a target and another as a ligand. The results show that the two porphyrins are arranged parallel to each other (Fig. 8).

Table 6 shows the results of the dimerization of anionic and cationic porphyrin. Firstly, the dimerization free energy for cationic is more negative than anionic, secondly in both ligands, the first rank is the most probable docking site due to their higher cluster rank. The anionic ligand has more numbers of occurrences in the first cluster. We defined net tendency for docking (NTD) and $\Delta \Delta G$ as follows:

$$
\begin{gathered}
\mathrm{NTD}=\left(\Delta G_{\mathrm{doc}}-\Delta G_{\mathrm{dim}}\right) \\
\Delta \Delta \mathrm{G}=\mathrm{NTD}_{\text {anionic }}-\mathrm{NTD}_{\text {cationic }}
\end{gathered}
$$


$\Delta \Delta \mathrm{G}$ is the difference of tendency between anionic and cationic for docking to ADA. $\Delta G_{\mathrm{doc}}$ and $\Delta G_{\mathrm{dim}}$ have been taken from Table 4 and 6 respectively. Since, this value is negative in all three conditions, the tendency of anionic for binding to ADA relative to dimerization is higher than cationic (Table 7). Thus, docking results are now compatible with experimental bindings.

\section{Conclusion}

Kinetic and structural studies have been performed on the effect of anionic and cationic porphyrins on adenosine deaminase (ADA) using different methods and techniques. The structural changes of ADA in the presence of two porphyrins were investigated by molecular dynamics. Kinetic results showed that two porphyrins are non-competitive inhibitors. Increasing $\mathrm{pH}$ causes an increase in $K_{\mathrm{I}}$ and in all $\mathrm{pHs}$ the cationic type has higher $K_{\mathrm{I}}$. Binding constants obtained by fluorescence spectrophotometry are compatible with kinetic results. The anionic porphyrin has a higher binding constant compared to the cationic porphyrin. There was a difference in the trend of docking energy taken from Autodock (cationic is more negative) and binding energy taken form fluorescence and kinetic for anionic and cationic (anionic is more negative). This conflict was removed by considering the dimerization energy. In a comparison of tryptophans, the porphyrins tend to bind Trp117. ADA in the presence of porphyrins was also studied by MD. Secondary structure also decreases in lower $\mathrm{pH}$ and the anionic type is more effective on this trend. The results of computation and experimental secondary structure were compatible.

Acknowledgments. The financial support of Damghan University and University of Tehran are acknowledged. The authors also acknowledge Alireza Safari for editing the manuscript.

\section{References}

1. Spencer, N.; Hopkinson, D.; Harris, H. Ann. Hum. Geitet. 1968 32, 9-14.

2. Doddona, P. E.; Schewach, D. S.; Kelly, E. N.; Argos, P.; Markham, A. F.; Orkin, S. H. J. Biol. Chem. 1984, 259, 25912101.

3. Chang, Z.; Nygaard, P.; Chinualt, A. C.; Kellems, R. E. Biochemistry 1991, 30, 2273-2280.

4. Wilson, D. K.; Rudolph, F. B.; Quiocho, F. A. Science 1991, 252, 1278.

5. Farber, G.; Petsko, G. Trends. Biochem. Sci. 1990, 15, 228.

6. Hershfield, M.; Mitchell, B.; Scriver, C. R.; Beaudet, A. L.; Sly, W.; Valle, D., eds., The Metabolic and Molecular Basis of Inherited Disease, 17th ed.: McGraw-Hill, New York, 1995, 1725.

7. Van der Weyden, M.; Kelley, W. J. Biol. Chem. 1976, 257, 5448.

8. Baghanha, M. F.; Pego, A.; Lima, M. A. Chest. 1990, 87, 605.

9. Hovi, T.; Smyth, J. F.; Allison, A. C.; Williams, S. C. Clin. Exp. Immunol. 1976, 23, 395.

10. Sullivan, J. L.; Oxborne, Wedgewood, R. J. Br. J. Haematol. 1977, $37,157$.

11. Edwards, Y.; Hopkinson, D. Harris, H. Ann. Human Genet. 1971, 35, 207.

12. Bi, M. K.; Klü S.; Meriç, Y.; Ylmaz, F.; Baar, O.; Ylmaz, G.;
Yüksel, O.; Yldrm, E.; Ztürk, Z. Pancerat. 2007, 7, 5.

13. Kaisemann, M.; Kritski, A.; Pereira, M.; Trajman, A. J. Bras. Pneumol. 2004, 30, 549.

14. Manjula, S.; Raja, A.; Rao, S.; Aroor, A.; Rao, A. Acta Neurochir. $1993,121,149$.

15. Yildirim, Z.; Hasanoglu, H.; Akyol, O.; Gokirmak, M.; Koksal, N. Clinic. Biochem. 1999, 32, 283.

16. Toshifumi, K.; Atsushi, I.; Seiji, S. Tetrahedron 2005, 61, 4881.

17. Rose, E.; Quelquejeu, M.; Pandian, R. P.; Lecas-Nawrocka, A.; Vilar, A.; Ricart, G.; Collman, P.; Wang Z.; Straumanis, A. Polyhedron 2000, 19, 581.

18. Macdonald, I. J.; Dougherty, T. J. J Porphyrins Phthalocyanines 2001, 5, 105.

19. Kawao, M.; Ozawa, H.; Tanaka, H. Ogawa, T. Thin Solid Films 2006, 499, 23.

20. Takechi, K.; Shiga, T.; Motohiro, T.; Akiyama, T.; Yamada, S.; Nakayama, H.; Kohama, K. Solar Energy Mater. Sol. Cells 2006, 90, 1322.

21. Ogawa, K.; Zhang, T. Q.; Yoshihara, K.; Kobuke, Y. J. Am. Chem. Soc. 2002, 124, 22.

22. Li, Y.; Cao, L.; Tian, H. J. Org. Chem. 2006, 71, 8279.

23. Pandey, R. K.; Zheng, G.; Kadish, K. M.; Smith, K. M.; Guilard, R., Eds.; Academic Press: New York, 2000, 6, 157.

24. Scolaro, L. M.; Romeo, A.; Pasternack, R. F. J. Am. Chem. Soc. 2004, 126, 7178 .

25. Purrello, R.; Raudino, A.; Scolaro, L. M.; Loisi, A.; Bellacchio, E.; Lauceri, R. J. Phys. Chem. B 2000, 104, 10900.

26. Borissevitch, I. E.; Tominaga, T. T.; Imasato, H.; Tabak, M. Anal. Chim. Acta 1997, 343, 281.

27. White, W. I. in Dolphin, D.; Ed.; Academic Press: New York, 1978, 5, 303.

28. Scolaro, L. M.; Castriciano, M.; Romeo, A.; Mazzaglia, A.; Mallamace, F.; Micali, N. Physica A 2002, 304, 158.

29. Micali, N.; Villari, V.; Scolaro, L. M.; Romeo, A.; Castriciano, M. A. Phys. Rev. E 2005, 21, 64, 72.

30. Ajloo, D.; Saboury, A. A.; Haghi-Asli, N.; Ataie-Jafari, G.; Mossavi-Movahedi, A. A.; Ahmadi, M.; Mahnam, K.; Namaki, S. J. Enz. Inhib. Med. Chem. 2007, 22, 395.

31. Ajloo, D.; Najafi, L.; Saboury, A. A. Bull. Korean Chem. Soc. 2009, 30, 2523.

32. Ajloo, D.; Taghizadeh, E.; Saboury, A. A.; Bazyari, E.; Mahnam, K. Int. J. Biol. Macromol. 2008, 43, 151 .

33. Ajloo, D.; Behnam, H.; Saboury, A. A.; Mohamadi-Zonoz, F.; Ranjbar, B.; Moosavi-Movahedi, A. A.; Hasani, Z.; Alizadeh, K.; Gharanfoli, M.; Amani, M. Bull. Korean Chem. Soc. 2007, 28, 730 .

34. Adler, A. D.; Lango, F. R.; Finarlli, J. D.; Goldmacher, J. G.; Assour, J.; Koisakoff, L. J. Org. Chem. 1967, 32, 476.

35. Kaplan, N. O. Academic Press: New York, Meth. Enzymol. 1955, 2,473 .

36. Froehlich, E.; Mandeville, J. S.; Jennings, C. J.; Sedaghat-Herati, R.; Tajmir-Riahi, H. A. J. Phys. Chem. B 2009, 113, 6986.

37. Morris, G. M.; Goodsell, D. S.; Huey, R.; Olson, A. J. J. Comput. Aided Mol. Des. 1996, 10, 293.

38. Van Der Spoel, E.; Lindahl, B.; Hess, G.; Groenhof, A. E.; Mark, H. J.; Berendsen, H. J. C. Comput. Chem. 2005, 26, 1701.

39. Van Gunsteren, W. F.; Billeter, S. R.; Eising, A. A.; Hunenberger, P. H.; Kruger, P.; Mark, A. E.; Scott, W. R. P.; Tironi, I. G.; Biomolecular Simulation: The GROMOS96 Manual and User Guide, Zürich, Switzerland, Groningen, Holland, 1996.

40. Berendsen, H. J. C.; Postma, J. P. M.; van Gunsteren, W. F.; Hermans, J. In Intermolecular Forces; B. Pullman, Ed.; Reidel: Dordecht, Holland 1981, 331.

41. Verlet, L. Phys. Rev. 1967, 159, 98.

42. Darden, T.; York, D.; Pedersen, L. J. Chem. Phys. 1993, 98 , 10089.

43. Hess, B.; Bekker, H.; Berendsen, H. J. C.; Fraaije, G. E. M. J. Comput. Chem. 1997, 18, 1463. 
44. Nosé, S. A. Mol. Phys. 1984, 52, 255.

45. Hoover, W. G. Phys. Rev. A 1985, 31, 1695.

46. Parrinello, M.; Rahman, A. Phys. Rev. Letters 1980, 45, 1196.

47. van Aalten, D. M. F.; Bywater, R.; Findlay, J. B.; Hendlich, M.; Hooft, R. W.; Vriend, G. J. Comput. Aided Mol. Des. 1996, 10,
255.

48. Willard, L.; Ranjan, A.; Zhang, H. Monzavi, H.; Boyko, R. F.; Sykes, B. D.; Wishart, D. S. Nucleic Acids Res. 2003, 31, 3316.

49. Segel I. H. Enzyme Kinetic, John Wiley and Sons: New York. 1993. 